\title{
BIBLIOGRAPHY
}

\section{Archives and libraries}

Arquivo Histórico-Social, National Library of Portugal, Lisbon

Arxiu Històric de la Ciutat de Barcelona, Barcelona

Biblioteca CRAI, Pavelló de la República, Barcelona

Biblioteca Popular José Ingenieros, Buenos Aires

Centre International de Recherches sur l'Anarchisme, Lausanne

Centro de Documentación e Investigación de la Cultura de Izquierdas en Argentina,

Buenos Aires

International Institute of Social History, Amsterdam

The British Library, London

\section{Primary sources}

Anon., 'Sección doctrinal. La teoría darwiniana', La Humanidad, 31 (1871), $247-248$

Anon., 'Arte y ciencias. Cárlos Darwin (1)', Revista Social, 51 (1882), 3-4

Anon., 'Notre programme', Régénération. Organe de la Ligue de la Régénération Humaine, flier, (1896)

Anon., 'Puériculture pratique', Régénération. Organe de la Ligue de la Régénération Humaine, 10 (1902), 3

Anon., 'The Américan [sic] Journal of Eugenics', Régénération, 32 (1907), 281

Anon., 'À Tous!', Génération Consciente, 1 (1908), 1

Anon., 'Ao aparecer', A Sementeira, 1 (1908), 1

Anon., 'Publicações recebidas', A Sementeira, 4 (1908), 31

Anon., 'Déterminisme', L’Anarchie, 193 (1908), 2

Anon., 'Anti-militarismo', A Sementeira, 7 (1909), 49

Anon., 'As diversas escolas libertarias', A Vida: Após o 'Despertar', Folha Semanal, 7 (1909), 1

Anon., 'L'amélioration de la race humaine est-elle possible?', Le Malthusien, 17

(1910), 134 
Anon., 'Séléction à rebours', Génération Consciente, 29 (1910), 2

Anon., 'Bureau Internacional Neo-Maltusiano', O Agitador. Semanario anarquista, 1 (1911), 2

Anon., 'Convocations. Groupe d'Études Sociales et Groupe ouvrier Néo-Malthusien des XI ${ }^{\mathrm{e}}$ et XII ${ }^{\mathrm{e}}$, Les Temps Nouveaux, 17:49 (1912), 7

Anon., 'Who Are the Feeble-Minded?', Freedom, 281 (1912), 68-69

Anon., 'Phrenologists and Eugenics', Freedom, 283 (1912), 87

Anon., 'Faits et documents. La Société Française d'Eugénique', Le Malthusien, 53 (1913), 421

Anon., 'Eugenics and Faddists', Freedom, 291 (1913), 53

Anon., 'Faits et documents. Eugénisme et étatisme', Le Malthusien, 65 (1914), $517-518$

Anon., 'Conocimientos útiles. Para las madres', La Protesta, 2237 (1914), 3

Anon., 'Cartel para los desocupados', La Protesta, 2704 (1915), 4

Anon., 'Glossário', A Sementeira, 64 (1916), 6

Anon., [Hardy, G.], 'Le Néo-Malthusien est interdit. La Grande Question est interdite. Voici le Néo-Malthusianisme', Le Néo-Malthusianisme, 1 (1917), 1

Anon., 'La natalidad en Europa', La Protesta, 3812 (1920), 1

Anon., 'A los amantes de la Humanidad', Eugenia, 1 (1921), 2-3

Anon., 'De Eugenismo. Perfección Humana', Eugenia, 2 (1921), 13

Anon., 'Aclaración', Eugenia, 3 (1921), 21

Anon., 'Eugenesia guerrera', La Protesta, 3918 (1921), 1

Anon., 'Sir Francis Galton', Eugenia, 12-14 (1922), 98-99

Anon., 'Presentación', Generación Consciente, 1 (1923), 1

Anon., 'P. Gregorio Méndel', Eugenia, 24 (1923), 213-215

Anon., 'Birth Control Banned', Freedom, 403 (1923), 1

Anon., 'Helping the Birth-Rate', Freedom, 404 (1923), 7

Anon., 'Who Are the Unfit?', Freedom, 412 (1923), 61

Anon., 'Apuntes bibliográficos', La Revista Blanca, I (9) (1923), 26

Anon., [no title], Renovação. Revista quinzenal de arte, literatura e actualidade, 1 (1925), 1

Anon., 'Na Universidade Popular. Higiene e puericultura', A Batalha, 1388 (1925), 1

Anon., 'Attack on Birth Control', Freedom, 440 (1927), 7

Anon., 'Eugenics Run Mad', Freedom, 442 (1927), 21

Anon., 'Origens verdadeiras da prostituição', A Batalha, 2845 (1927), 1

Anon., 'Programa Social Eugénico', Eugenia, 72 (1928), 58-60

Anon., 'Bases eugénicas para una nueva sociedad', Eugenia, 73 (1928), 66-70

Anon., 'Movimiento de propaganda eugénica en España', Eugenia, 73-74 (1928), 70

Anon., 'El primer curso eugénico español', Eugenia, 75 (1928), 74-75

Anon., 'La jornada de 6 horas. Una resolución del congreso de Lieja de la A. I. de los Trabajadores', La Protesta, 6008 (1928), 1

Anon., 'Superioridad de raza', La Protesta, 6028 (1928), 1

Anon., 'El número como fuerza', La Protesta, 6071 (1928), 1

Anon., 'Revisiones. Del momento político', Estudios, 79 (1930), 1-2

Anon., 'La stérilisation des humains indésirables', Le Libertaire, 250 (1930), 1

Anon., 'Programme de la Ligue Mondiale pour la Réforme Sexuelle sur une base scientifique', La Grande Réforme, 1 (1931), 2 
Anon., 'Nudismo e Naturismo', O Vegetariano. Jornal de Higiene, Terapeutica Natural, Horticultura, Pomicultura, Floricultura, Educação e Turismo, 7-8 (1931), 50

Anon., 'A Confederação Geral do Trabalho ante a legislação corporativa', A Batalha, 1 (1934), 1

Anon., 'O “nacionalismo” dos farsantes!', A Batalha, 2 (1934), 4

Anon., 'Dîners eugénistes. Se connaître, s’aimer, s'entr'aider', La Grande Réforme, 36 (1934), 2

Anon., 'Contre le fascisme', La Grande Réforme, 38 (1934), 2

Anon., 'Hitler, el tirano de Alemania, es Judío', La Protesta, 7836 (1935), 2

Anon., 'Concepto confederal del Comunismo libertario', La Revista Blanca, 384 (1936), 440-443

Anon., 'Procreación iluminada y consciente', Cultura Sexual y Física, 4 (1937), 206-207

Anon., 'Actividades de Mujeres Libres', Mujeres Libres, 9 (1937), n.p.

Anon., 'Nuevas conquistas para Asistencia Social', Mujeres Libres, 10 (1937), n.p.

Anon., 'Maternidad', Mujeres Libres, 11 (1937), n.p.

Anon., 'Un acontecimiento histórico', Mujeres Libres, 11 (1937), n.p.

Anon., '28.000 Mujeres', Mujeres Libres, 11 (1937), n.p.

Anon., 'Carteles de la España revolucionaria', La Protesta, 7853 (1937), 1

Anon., 'Maternidad', Mujeres Libres, 13 (1938), n.p.

Anon., 'Puericultura', Mujeres Libres, 13 (1938), n.p.

Anon., 'Nos buts', La Grande Réforme, 82 (1938), 5

Anon., 'La generación va siendo más consciente', La Protesta, 7873 (1938), 1

Anon., 'The Geneticists' Manifesto', in H. Gruenberg, 'Men and Mice at Edinburgh:

Reports from the Genetics Congress', Journal of Heredity, 30:9 (1939), 371-374

Aldred, G. A., The Religion and Economics of Sex Oppression (London: Bakunin Press, 1907)

Amador, N., 'El factor biológico de la estructura social. Política nacional Eugénica', Eugenia, 41 (1924), 53-57

Amador, N., 'El factor biológico de la estructura social. Política nacional Eugénica', Eugenia, 42 (1924), 71-75

Amador, N., 'El factor biológico de la estructura social. Política nacional Eugénica', Eugenia, 43 (1924), 88-92

Amador, N., 'Herencia y Eugénica', Generación Consciente, 17 (1924), 213-215

Amador, N., 'Herencia y Eugénica', Generación Consciente, 18 (1925), 229-231

Amador, N., 'El factor biológico en la pedagogía. Educación y Herencia', Eugenia, 53 (1925), 233-236

Apert, E., 'Allocution du Dr. E. Apert, Président. - L'importance sociale des études eugéniques', Fédération Internationale Latine des Sociétés d'Eugénique, $1^{\text {er }}$ Congrès Latin d'Eugénique. Rapport (Paris: Masson et C $\left.C^{\mathrm{ie}}, 1937\right)$, pp. 7-12

Aracemi, M., 'El Amor libre', La Protesta. Suplemento mensual, 4 (1908), 82-84

Aracemi, M., 'El perfeccioniamiento individual', La Protesta, 1579 (1909), 1

A[rmand], E., 'Quelques critiques de l'Eugénisme', L'En Dehors, 147 (1928), 5-6

A[rmand], E., 'Quelques critiques de l'Eugénisme', L'En Dehors, 148-149 (1928), $5-6$

Armand, E., 'El Malthusianismo, el neo-Malthusianismo y el punto de vista individualista', Salud y Fuerza, 43 (1911), 106-108 
Armand, E., 'El Malthusianismo, el neo-Malthusianismo y el punto de vista individualista (Conclusión)', Salud y Fuerza, 44 (1911), 118-121

Armand, E., 'Le bluff criminologiste', L'En Dehors, 11-12 (1923), 1

Armand, E., 'L'affaire des stérilisations', La Voix Libertaire, 301 (1935), 2

Armand, E., La révolution sexuelle et la camaraderie amoureuse, ed. G. Manfredonia (Paris: Zones, 2009)

Artignac, A., 'La Question néo-mathusienne [sic]', Le Libertaire, 22 (1900), 5

Austin, K., 'La cuestión sexual', La Protesta, 3084 (1917), 1-2

Bartosek, N., La Stérilisation Sexuelle. Son importance Eugénique, Médicale, Sociale (Brussels: Éditions 'Pensée et Action', 1920)

Bartosek, N., 'Le Cas Chatain et la Stérilisation légale', La Grande Réforme, 81 (1938), 3

Bernaldo de Quirós, C., 'Psicología del crimen anarquista', Archivos de Psiquiatría, Criminología y Ciencias Afines, 12 (1913), 122-126

Berneri, C., El delirio racista, trans. Armando Panizza (Buenos Aires: Imán, 1935)

Bieri, J., 'Ventajas é inconvenientes del neo-Malthusianismo', La Protesta, 1586 (1909), 2

Bieri, J., 'Ventajas é inconvenientes del neo-Malthusianismo', La Protesta, 1587 (1909), 2

Bieri, J., ‘¿Malthus ó Neo-Malthus?', La Protesta, 1604 (1909), 1

Bombarda, M., 'Eugenese', A Medicina Contemporanea, 13:8 (1910), 57-58

Bonafulla, L., La Familia Libre (Barcelona: Taberner Editor, no date [c. 1910])

Bosio, B., 'Desde Temprano ha de Iniciarse la Educación Sexual del Niño', Cultura Sexual y Física, 6 (1938), 343-344

Boyant, M. M., 'Es admisible el neo-malthusianismo como precipitante de la transformación social?', La Protesta, 1541 (1909), 1

Brasil, J., 'Problemas actuais. A "procriação voluntária” em nome dos superiores interesses da espécie', O Globo. Hebdomadário de cultura, doutrina e informação, 18 (1930), 2

Brasil, J. O Problema Sexual (Lisbon: Editora Portugal Ultramar, 1931)

Brasil, J., Os Padres e 'A Questão Sexual'. Resposta a uma campanha do jornal católico 'Novidades' (Lisbon: Casa Editora Nunes de Carvalho, 1932)

Brasil, J., A Questão Sexual (Lisbon: Nunes de Carvalho, 1932)

Brasil, J., A Procriação Voluntária. Processos para evitar a gravidez (Lisbon: Nunes de Carvalho, 1933)

Brezosa Tablares, P., 'Maltusianismo, Neo-maltusianismo', Eugenia, 43 (1924), $85-87$

Briand, H., 'Les progrès de l'eugénique et de la génétique en France au cours des dernières années', Revue Anthropologique, 48 (1938), 307-314

Broutchoux, B., 'La Sociedad Burguesa y sus "neo detractores"', Salud y Fuerza, 1 (1904), 4-5

Broutchoux, B., 'La Sociedad Burguesa y sus “neo-detractores"', Salud y Fuerza, 2 (1905), 12-13

Bruno, G., 'Transformismo', A Vida: Após o 'Despertar', Folha Semanal, 99 (1907), 3

Bruno, M., 'Contre le lapinisme', La Voix Libertaire, 112 (1931), 1

Buchner, L., 'Un dilema', Natura, 2 (1903), 21 
Buchner, L., 'L'Individu et la Société', L'Idée Libre. Revue Mensuelle d'Education sociale, Science, Philosophie, Littérature, 9 (1912), 201

Bueno, J., ‘¿Neo-Malthusianismo?’, La Protesta, 2253 (1914), 2

Bulffi, L., 'Dos palabras', Salud y Fuerza, 1 (1904), 1

Bulffi, L., 'El fracaso de la revolución por la miseria', El Nuevo Malthusiano, 2 (1905), 9-11

Bulf[f]i, L., Gréve [sic] de Ventres! (Oporto: Secção Portuguesa da Liga da Regeneração Humana, 1906)

Cabezón, P., 'La Ley de Malthus', La Protesta, 387 (1904), 3

Campollano, F. de, 'La esterilización eugénica y los legófilos', Estudios, 129 (1934), 30-32

Canosa, F.R., 'La selección del Inmigrante', La Protesta, 2631 (1915), 2

Canosa, F.R., 'La guerra y la miseria', La Protesta, 2691 (1915), 2

Carbonell, J.F., 'Feminismo y marimachismo', Eugenia, 6 (1921), 53-57

Carulla, J.E., 'El mal de los pintores', Ideas y Figuras, 70 (1912), 1-7

Castet, G., 'Les Eugénics', Le Malthusien, 23 (1910), 180

Charles-Albert, 'Science et révolution', Les Temps Nouveaux, 5 (1896), 1-3

Chueca, J., 'Necesidad del neo-Malthusianismo', Salud y Fuerza, 52 (1913), $244-245$

Chueca, J., 'Nueva humanidad', Salud y Fuerza, 55 (1913), 290-292

Chueca, J., 'Eugenesia y Neomalthusianismo', Salud y Fuerza, 57 (1914), 321-322

Chueca, J., 'La eficacia de la escuela', in the Argentinian La Escuela Popular. Revista mensual. Órgano de la Liga de Educación Racionalista, 15 (1914), $18-20$

Cid, N., ‘Mocidade vivei!... O Neo-Malthusianismo', Germinal, 21 (1912), 2

Cid, N., 'O Neo-Maltusianismo V. O aumento da população e a questão economica A familia burgueza e o proletario - A necessidade do neo-maltusianismo', Germinal, 28 (1912), 2

Cid, N., 'O Neo-Maltusianismo XVII. A pornografia e os neo-maltusianistas Nudez e naturismo - O problema sexual e a civilisação moderna', Germinal, 42 (1912), 2-3

Cid, N., 'O Neo-Maltusianismo XXIV. A prostituição e as suas cauzas - neomaltusianismo como agente de profilaxia social - conceções e convicções', Germinal, 57 (1912), 2

Cid, N., 'Neo-Maltusianismo XXIX', Germinal, 79 (1913), 2

Ciquis, 'La influencia del medio ambiente como pretendida justificación de los errores del hombre', La Protesta, 2853 (1916), 1

Cohen, F., 'Love and Marriage', The Spur: Because the Workers Need a Spur, 2 [printed as number 1] (1915), 12-14

Cohen, F. et al., 'Love and Marriage. Discussion', The Spur, 4 (1915), 28-30

Comité pour L'Amnistie, Le, 'Notre action pour l'amnistie. Liberté pour les victimes de 1920. Liberté pour les propagandistes néo-malthusiens', Le Libertaire, 378 (1932), 1

Confederação dos Grupos Operários Neomalthusianos, Procriação Consciente (páginas de práticas néo-malthusianas) (Lisbon: Edição de A Sementeira, no date [1922])

Corazón y Cerebro, 'Degeneración y vicio', Ideas, 123 (1924), 4 
Cortês, L., 'Higiene social. O alcoolismo, factor da degenerescência física, deve ser suprimido dos nossos hábitos', A Batalha, 1944 (1925), 4

Costa-Iscar, 'Gran conferencia - controversia. El Naturismo y el problema humano', La Protesta, 4390 (1923), 2

Cuadrado, A., 'Nuestra labor en la Casa de Maternidad de Barcelona', Mujeres Libres, 7 (1937), n.p.

Darwin, L., What is Eugenics? (London: Watts, 1928)

Dave, V., 'Luiz Büchner', A Sementeira, 28 (1910), 223-225

Day, H., 'La verdadera educación sexual', La Revista Blanca, VII (161) (1930), 407-409

Day, H., 'Comité por la libération de N. Bartosek', La Voix Libertaire, 298 (1935), 2

Day, H., 'La esterilización sexual', Estudios, 139 (1935), 14-16

Day, H., La stérilisation et le point de vue anarchiste (Brussels: Pensée et Action, no date)

De la Veyga, F., 'Delito político. El anarquista Planas Virella', Archivos de Psiquiatría, Criminología y Ciencias Afines, 5 (1906), 513-548

Del Valle, A., 'Los factores de degeneración', Eugenia, 49 (1925), 189-191

Delage, Y. and Goldsmith, M., 'O Darwinismo', A Sementeira, 35 (1911), 279-280

Delfino, V., 'Divulgaciones científicas. La herencia en el hombre desde los puntos de vista normal y patológico', La Protesta, 2816 (1916), 3

Dercu, J., 'Sobre neomalthusianismo', La Protesta, 2250 (1914), 2

Devaldès, M., 'Lapinisme et patriotisme', Le Libertaire, 42 (1905), 1

Devaldès, M., 'Malthus et le Droit de Vivre', Génération Consciente, 5 (1908), 1

Devaldès, M., 'Contre la guerre par la limitation des naissances', Génération Consciente, 7 (1908), 1

Devaldès, M., Malthusianismo y Neo-Malthusianismo, trans. José Prat (Barcelona: Biblioteca Editorial Salud y Fuerza, 1908)

Devaldès, M., 'La Bonne Nature', Génération Consciente, 11 (1909), 1

Devaldès, M., La Maternité consciente. Le Rôle des Femmes dans l'Amélioration de la Race (Paris: Éditions Radot, 1927)

Devaldès, M., 'La stérilisation eugénique aux États-Unis', La Grande Réforme, 29 (1933), 3

Devaldès, M., 'La esterilización eugénica en los Estados Unidos', Estudios, 123 (1933), 40-42

Devaldès, M., 'La stérilisation en Allemagne et l'Église Catholique', La Grande Réforme, 37 (1934), 1-2

Devaldès, M., 'La surpopulation allemande et la guerre qui vient', La Grande Réforme, 43 (1934), 1-2

Drysdale, C. V., Can Everyone Be Fed? A Reply to Prince Kropotkin (London: The Malthusian League, 1913)

Ellis, H., 'Limitation des naissances, Moralité, Eugénie', Le Néo-Malthusien, 6 (1919), 3-4

Ellis, H., 'Limitation des naissances, Moralité, Eugénie', Le Néo-Malthusien, 7 (1919), 1-2

Esgleas, G., 'Ensayo crítico-literario sobre “El Hijo de Clara”', La Revista Blanca, VII (111) (1928), 459-464 
Fages, C., 'L'Evolution du Darwinisme sociologique', L'Humanité Nouvelle, 3:1 (1899), 28-42

Faure, S., La Douleur Universelle (Paris: P. V. Stock, 1921)

Faure, S., 'Alrededor del asunto de las esterilizaciones', Estudios, 142 (1935), 3-5

Faure, S., 'Autour de l'affaire des stérilisations', Le Libertaire, 444 (1935), 1 and 3

Federn, E., 'Maternidad y maternalidad', Mujeres Libres, 12 (1938), 32-33

Fernandes, A., 'Sejamos naturistas', O Agitador. Semanario anarquista, 2 (1911), 2

Formenti, A., 'Maternidad consciente', Ideas, 198 (1929), 6-7

Fouillé, A., 'Las falsas consecuencias morales y sociales del darwinismo', Natura, 41 (1905), 266-272

Fouillé, A., 'El Darwinismo. Sus falsas consecuencias morales y sociales', La Protesta, 577 (1905), 3-4

Fouillé, A., 'El Darwinismo. Sus falsas consecuencias morales y sociales', La Protesta, 578 (1905), 3-4

Fraigneux, R., 'A repressão do néo-maltusianismo', O Agitador. Semanario anarquista, 1 (1911), 1-2

Fromentin, A., 'Dégénérés Sociaux', L'Idée Libre, 13 (1912), 1-5

G., 'Procriae!', Novos Horisontes. Publicação mensal operaria de propaganda e de critica, 1 (1906), 7

G. I., 'El derecho a la vida', La Protesta Humana, 36 (1898), 1

Galton, F., 'Hereditary Talent and Character', MacMillan's Magazine, 12:68 (1865), 157-166, and, 318-327

Galton, F., Hereditary Genius (London: Macmillan, 1869)

Galton, F., Inquiries into Human Faculty (London: Macmillan, 1883)

Galton, F., 'Eugenics, Its Definition, Scope and Aims', Nature, 70:1804 (1904), 82

Girard, A., 'Paul Robin', Lumen: a vida e o ideal - Critica, Sociologia e Arte, 13 (1912), 1-2

Giribaldi, F., 'El neo-malthusianismo', La Protesta, 2242 (1914), 1

Giribaldi, F., 'Sobre malthusianismo', La Protesta, 2246 (1914), 2

Giribaldi, F., 'El problema de la desocupación', La Protesta, 5930 (1928), 2

Gottschalk, A., 'Le Néo-Malthusianisme et la Santé', Le Malthusien, 16 (1910), $121-122$

Grandjean, V., 'Malthusianisme', L’Exploitée, 1 (1907), 4

Grau, H., 'Desde la Argentina. Consideraciones neo-malthusianas', Salud y Fuerza, 40 (1910), 49-50

Grau, H., 'Desde la Argentina', Salud y Fuerza, 41 (1911), 77-79

Grau, H., 'Crónica argentina', Salud y Fuerza, 44 (1911), 122-125

G[rave], J., 'La influencia del medio', La Protesta, 2788 (1916), 1.

Grave, J., 'Harmonía - Solidaridad', La Protesta Humana, 32 (1898), 1-2

Grave, J., 'La Société Bourgeoise et ses «Néo» Défenseurs', Les Temps Nouveaux, 10:17 (1904), 1-2

Grave, J., 'La influencia del medio', Germen. Revista Mensual de Sociología, 6 (1907), 166

Grave, J., La société des nations (Paris: Administration et Rédaction, 1918)

Gros, A., 'Aux lecteurs', Le Malthusien, 1 (1908), 1

Grupo Editor de 'Natura', 'Nuestros propósitos', Natura, 1 (1903), 1-3 
Grupo Pro-Eugenismo, Eugenismo. Nueva Orientación Social. Bases eugénicas que el Grupo Pro-Eugenismo presenta a la consideración de los hombres de buena voluntad (Barcelona: Biblioteca Eugenia, 1931)

Guyau, M., 'La Vida', Natura, 46 (1905), 337-340

Guyau, M., 'Esbozo de una moral sin obligación ni sanción', La Protesta, 577 (1905), 1

Haldane, J. B. S., 'Une opinion sur la stérilisation', La Grande Réforme, 273-274 (1934), 160

Haldane, J. B. S., Heredity and Politics (London: George Allen and Unwin, 1938)

Hamon, A., 'La Libertad', Natura, 1 (1903), 12-16

Hardy, G., 'La lucha por la existencia y el neo-Malthusianismo', Salud y Fuerza, 1 (1904), 2-4

Hardy, G., 'Néo-malthusisme et Révolution', Génération Consciente, 46 (1912), $1-2$

Hardy, G., 'La Vasectomie', L’Idée Libre, 21 (1913), 208-210

Hardy, G., 'Eugénie, puériculture', Le Néo-Malthusien, 5 (1919), 7-8

Hardy, G., 'The Situation in France', in Margaret Sanger (ed.), International Aspects of Birth Control (New York: American Birth Control League, 1925), pp. 33-40

Hardy, G., 'Eugénésie', La Grande Réforme, 4 (1931), 2

Houssay, F., 'Eugénique et régimes alimentaires', Eugénique. Organe de la Société française d'Eugénique, 1:1-4 (1913), 1-9

Huerta, L., 'Cultivo de la paternidad', Eugenia, 15 (1922), 116-119

Huerta, L., 'Cultivo de la paternidad', Eugenia, 16 (1922), 132-136

Huerta, L., 'La ciencia de Galton', Eugenia, 25 (1923), 230-234

Huerta, L., 'La ciencia de Galton', Eugenia, 26 (1923), 249-253

Huerta, L., ‘¿Herencia o “transpulsión”?’, Estudios, 65 (1929), 8-10

Huerta, L., 'El Malthusianismo no es el Eugenismo', Estudios, 77 (1930), 36-43

Hulot, L., 'Contre la Dégénérescence', L’Anarchie, 132 (1907), 2-3,

Hulot, L., 'Contre la Dégénérescence', L’Anarchie, 133 (1907), 3

Humbert, E., 'Prevenir le mal', La Grande Réforme, 15 (1932), 1

Humbert, E., 'Les “stérilisés” de Vienne', La Grande Réforme, 18 (1932), 2

Humbert, E., 'Dégénérescence - Régénération', La Grande Réforme, 25 (1933), 1

Humbert, E., 'À nos amis. Dîners eugénistes', La Grande Réforme, 31 (1933), 2

Humbert, J., Eugène Humbert. La vie et l'œuvre d'un néo-malthusien (Paris: La Grande Réforme, 1947)

Huraño, J. el, 'El neomalthusianismo y los anarquistas', Generación Consciente, 20 (1925), 306-307

Huxley, T. H., 'The Struggle for Existence in Human Society' (1888) in T. H. Huxley, Evolution and Ethics, and Other Essays (London: Macmillan, 1903), pp. $195-236$

Ignorantibus, 'Una causa de la degeneración. El alcoholismo', La Protesta, 2460 (1915), 3

Ignorantibus, 'La herencia y la educación', La Protesta, 2481 (1915), 3

Ilurtensis, 'AAmaos, pero no os multipliquéis! Neomaltusianismo, maternidad consciente y esterilización', Estudios, 125 (1934), 12-14

Ilurtensis, 'Eugenesia y educación social', Estudios, 129 (1934), 5-6 
Incógnito, 'Neomalthusianismo. Datos que pueden interesar', La Protesta, 1547 (1909), 2

Jacquinet, C., 'Reflexiones', Natura, 4 (1903), 56-57

Jóvenes, C., 'La nueva mesa de valores', Natura. Revista Quincenal de Ciencia, Sociología, Literatura y Arte, 3 (1903), 39-41

Juarros, [C.], 'Esterilización de los antisociales', Eugenia, 49 (1925), 183

Kleyman, G., 'Dépopulation', Le Libertaire, 29 (1896), 3

Kropotkin, [P.], 'Mutual Aid Among Animals', part I, The Nineteenth Century, 28 (1890), 337-354

Kropotkin, [P.], 'La moral anarquista', La Protesta Humana, 8 (1897), 3

Kropotkin, P., 'The Sterilization of the Unfit', Mother Earth, 7:10 (1912), 354-357

Kropotkin, P., 'Inheritance of Acquired Characters. Theoretical Difficulties', The

Nineteenth Century and After, 71 (1912), 511-531

Kropotkin, P., 'The Sterilisation of the Unfit', Freedom: A Journal of Anarchism Communism, 282 (1912), 77-78

Kropotkine, P., 'Comment lutter contre la dégénérescence. Conclusion d'un professeur de physiologie', Les Temps Nouveaux, 19:25 (1913), 2-3

Kropotkine, [P.], 'La lucha contra la degeneración de la raza', La Protesta, 2127 (1914), 3

Kropotkin, P., Ethics: Origin and Development, trans. Louis S. Friedland and Joseph R. Piroshnikoff (Montreal/New York: Black Rose Books, 1992 [1922])

Lamarck, J. B., Zoological Philosophy: An Exposition with Regard to the Natural History of Animals, trans. Hugh Samuel Roger Elliott (Cambridge: Cambridge University Press, 2011)

Laupts, Dr [pseudonym of Georges Saint-Paul], 'Déterminisme et responsabilité', L'Humanité Nouvelle, 3 (1898), 551

Layda, F., 'El criminal nato', La Protesta Humana, 101 (1900), 1

Lazarte, J., 'Orígenes de la Sexualidad', Cultura Sexual y Física, 19 (1933), 401-403

Lazarte, J., 'Significación cultural y ética de la limitación de los nacimientos', Estudios, 120 (1933), 14-16

Lazarte, J., El contralor de los nacimientos (Rosario: Librería Ruiz, 1936 [1934])

Le Libertaire, 'Ton corps est à toi!', Le Libertaire, 443 (1935), 1

Lecomte, A., 'La tâche des eugénistes', Le Malthusien, 49 (1912), 385-386

Lima, C., O Movimento Operario em Portugal (Lisbon: Guimarães \& $\mathrm{C}^{\mathrm{a}}$ Editores, 1910)

Lima, C., A Theoria Libertária ou o Anarquismo (Lisbon: Edições Spartacus, 1926)

Lisle, C. de, 'Em volta do amor livre', A Sementeira, 8 (1909), 58

Lisle, C. de, 'Em volta do amor livre', A Sementeira, 14 (1909), 110-111

Llunas, J., Estudios filosófico-sociales (Barcelona: Tipografía La Academia, 1882)

López Ureña, F., 'El individuo y la especie', La Revista Blanca, VII (149) (1929), 108-113

L[orenzo], [A.], 'El individuo contra el estado. Spencer y "La Revue Socialiste"', Acracia. Revista Sociológica, 1:2 (1886), 12-14

L[orenzo], [A.], 'El individuo contra el estado. Spencer y "La Revue Socialiste", Acracia. Revista Sociológica, 1:5 (1886), 34-36

Lorenzo, A., 'Ciencia burguesa y Ciencia obrera', Natura, 18 (1904), 273-278 
Lorenzo, A., El banquete de la vida. Concordancia entre la naturaleza, el hombre y la sociedad (Barcelona: Imprenta 'Luz', 1905)

Lorulot, A., 'Sur le déterminisme', L'Idée Libre, 9 (1912), 202-204

Lorulot, A., 'L'Humanité dégénère-t-elle?', L’Idée Libre, 17 (1921), 413-416

M. D., 'Ils viennent à l'eugénisme... mais ce sont des fascistes!', La Grande Réforme, 91 (1938), 3

Madrazo, [D. E.], 'Eugenesia. I’, Eugenia, 19-21 (1922), 168-172

Maestre y Pérez, 'Autopsia del anarquista Mateo Morral', Archivos de Psiquiatría, Criminología y Ciencias Afines, 6 (1907), 108-109

Mahé, A., 'L'hérédité et l'éducation', L'Anarchie, 94 (1907), 3

Malatesta, E., 'Determinismo y responsabilidad', La Obra. Publicación quincenal ilustrada, 3 (1915), 2

Malato, C., 'Páginas alheias. Riquesa e miséria', A Batalha, 1380 (1925), 4

Mantegazza, P., 'La esterilidad voluntaria', La Protesta. Suplemento mensual, 2 (1908), 51-54

March, L., 'Dépopulation et eugénique', Eugénique. Organe de la Société française d'Eugénique, 1:1-4 (1913), 10-40

March, L., 'El segundo congreso internacional de eugénica', Eugenia, 27 (1923), 265-270

Marconi y Caiola, D.C., 'El vegetalismo', La Protesta, 2174 (1914), 1

Marestan, J., L'Éducation Sexuelle. Anatomie, physiologie et préservation des organes génitaux. Moyens scientifiques et pratiques d'éviter la grossesse non désirée. Les raisons morales et sociales du néo-malthusianisme (Paris: Éditions de la 'Guerre Sociale', 1910).

Marestan, J., 'La Stérilisation est-elle un crime?’, La Grande Réforme, 49 (1935), 1

Margueritte, V., 'Légalisation du droit à l'avortement sous réserve du contrôle médical', La Grande Réforme, 5 (1931), 1-2

Marinot, L., 'Naturisme \& procréation consciente', La Grande Réforme, 23 (1933), 5

Martí Ibáñez, F., 'La revolución sexual', Estudios, 135 (1934), 3-5

Martí Ibáñez, F., 'Nueva moral sexual', Estudios, 134 (1934), 13-14

Martí Ibáñez, F., 'Consideraciones sobre el homosexualismo', Estudios, 145 (1935), $3-6$

Martí Ibáñez, F., 'La respuesta juvenil. Comentarios a una encuesta eugénica', Estudios, 141 (1935), 24-27

Martí Ibáñez, F., 'Mensaje eugénico a la mujer', Estudios, 159 (1936), 4-7

Martí Ibáñez, F., Mensaje engénico a los trabajadores (no publisher, no date [1936?])

Martí Ibáñez, F., Missatge eugènic als treballadors (no publisher, no date [1936?])

Martí Ibáñez, F., 'Mensaje eugénico a los trabajadores' [1936], in Ferran Aisa i Pàmpols, ECN 1. Radio CNT-FAI Barcelona. La voz de la Revolución (Barcelona: Editorial Entre Ambos, 2017), pp. 278-287

Martí Ibáñez, F., 'L'abolició del amor mercenari', S.I.A.S. Portanveu de la Conselleria de Sanitat i Assistència Social de la Generalitat de Catalunya, 1 (1937), 20-21

Martí Ibáñez, F., 'Una nueva moral sexual como base de las conquistas revolucionarias', Tiempos Nuevos, 2 (1937), 34-36 
Martí Ibáñez, F., 'En torno a la reforma eugénica del aborto’, Estudios, 160 (1937), 11-12

Martí Ibáñez, F., 'Sanidad, Asistencia social y Eugenesia en la Revolución social española', Estudios, 160 (1937), 34-38

Martí Ibáñez, F., La reforma eugénica del aborto (Barcelona: Ediciones de la Consejería de Sanidad y Asistencia Social, 1937), in J. V. Martí, and A. Rey, Antología de textos de Félix Martí Ibáñez (Valencia: Biblioteca Valenciana, 2004), pp. 135-142

Martí Ibáñez, F., Obra. Diez meses de labor en Sanidad y Asistencia Social (Barcelona: Tierra y Libertad, 1937)

Mascaux, Dr, 'Hygiène et Propreté Sexuelle', Génération Consciente, 1 (1908), $3-4$

Masgomieri, G., 'Anarquía y comunismo libertario. Necesidad previa de una estructuración orgánica social futura. (V y último). La obra cumbre', La Revista Blanca, XII (305) (1934), 939-940

Mauricius [pseudonym of Maurice Vandamme], 'Néo-Malthusianisme', L'Anarchie, 196 (1909), 2-3

Mauricius [pseudonym of Maurice Vandamme], 'Néo-Malthusianisme', L'Anarchie, 201 (1909), 4

Méline, J., 'La Décadence Anarchiste', L’Anarchie, 203 (1909), 2

Mella, R., 'Anarquía. - Su origen, progreso, evoluciones, definiciones é importancia actual y futura de este principio social', in Segundo Certamen Socialista. Celebrado en Barcelona el día 10 de Noviembre de 1889 en el Palacio de Bellas Artes (Barcelona: Establecimiento Tipográfico «La Academia», 1890), pp. $53-72$

Mella, R., ‘¿Otra vez?,' La Protesta (La Línea de la Concepción), 133 (1902), 1

Mendes, S., Socialismo libertario ou Anarchismo. História e doutrina (Coimbra: França Amaro, 1896 [1894])

Montemayor, C., 'Controversia con los católicos. ¿Con Moisés o con Darwin?', La Protesta, 3164 (1917), 2-3

Muller, H. J., 'La méthode d'évolution', L'En Dehors, 258-259 (1933), 141-142

Nettlau, M., De la crisis mundial a la anarquía (Eugenesia de la sociedad libre), trans. Diego Abad de Santillán (Barcelona: Ediciones Solidaridad Obrera, 1933)

Nido, E., 'El neo-malthusianismo', La Protesta, 2315 (1914), 3

Nido, E., 'El neo-malthusianismo', La Protesta, 2316 (1914), 3

Nieves, F., 'Desenvolvimiento del Neo-Malthusianismo en la Argentina', Salud y Fuerza, 43 (1911), 108-111

Noguera, E., 'Cómo se yuguló la generosa idea del Primer Curso Eugénico Español', in Enrique Noguera and Luis Huerta (eds), Libro de las primeras jornadas eugénicas españolas: Genética, eugenesia y pedagogía sexual, 2 vols., vol. II (Madrid: Morata, 1934), pp. 399-412

Ouguella, Visconde de [Carlos Ramiro Coutinho], A questão social. Evolução e socialismo (Lisbon: Antiga Casa Bertrand, José Bastos, 1896)

P., 'Regeneración y acracia', Acracia. Revista Sociológica, 1:1 (1886), 2-4

Pagán, E., Sexualismo libertario (Amor libre) (Valencia: Biblioteca de Estudios, 1933)

Paris, A., 'Communisme surpopulateur', La Grande Réforme, 60 (1936), 5-6

Patorni, A., 'Stérilisation légale des aliénés', La Grande Réforme, 86 (1938), 1 
Paul-Boncour, G., 'Congrès Pénal et Pénitentiare international de Berlin 1935', La Grande Réforme, 57 (1936), 5

Paula, R., 'Del régimen vegetariano-naturista y el malestar social', Eugenia, 3 (1921), 22-2

Perrier, R., 'La Eugênica [sic] y el mejoramiento de la raza', Salud y Fuerza, 52 (1913), 255-256

Perrier, R., 'La Eugénica y el mejoramiento de la raza', Salud y Fuerza, 53 (1913), 264-265

Perrier, R., 'L'Eugénique et l'amélioration de la race humaine', Le Malthusien, 55 (1913), 435-436

Poch y Gascón, A., 'La guerra y la degeneración de la especie', Estudios, 124 (1933), 31-33

Pottier [Potier], E., 'Malthus et Darwin', Le Malthusien, 5 (1909), 35-37

Pottier [Potier], E., 'Le Congrès Eugénique', Le Malthusien, 46 (1912), 361-364

Pottier [Potier], E., 'El Congreso Eugénico', Salud y Fuerza, 48 (1912), 185-187

Pottier [Potier], E., 'El Congreso Eugénico', Salud y Fuerza, 49 (1912), 199-202

Prat, J., 'A un amigo', Acción Libertaria, 27:1 (1901), 1

Pratelle, A., 'Mendelism', Freedom, 254 (1910), 45-46

Problems in engenics. Papers Communicated to the First International Eugenics Congress Held at the University of London, July 24th to 30th, 1912, vol. II, Report of proceedings of the First International Eugenics Congress Held at the University of London, July 24th to 30th, 1912 (London: Eugenics Education Society, 1912)

Proschowsky, A. R., 'L'Homosexualité relativement à la société', L'En Dehors, 19-20 (1923), 2

Proschowsky, A. R., 'L'Eugénisme', La Grande Réforme, 6 (1931), 3-4

Puente, I., 'Consideraciones eugénicas', Generación Consciente. Divulgaciones científicas. Revista quincenal de educación individual (Buenos Aires, no issue number, no date), pp. 16-17

Puente, I., 'Prólogo', in Manuel Devaldés, Profilaxis anticoncepcional. La Emancipación de la maternidad y de la paternidad no deseada, trans. J. L. P. (Buenos Aires: Sarmiento Casa Editora, no date), pp. 5-11

Puente, I., 'Eugenesia', Generación Consciente, 3 (1923), 33-34

Puente, I., 'Eugénica Preventiva', Generación Consciente, 20 (1925), 297-299

Puente, I., 'La raza de los pobres', Estudios, 68 (1929), 1-2

Puente, I., 'El “affaire” de esterilización de Burdeos', Estudios, 141 (1935), 17

Punnett, R. C., “'Le Mendelisme” et ses conséquences', L’Ėre Nouvelle, 50 (1910), 62-66

Quartim, P., Mocidade, vivei! (Lisbon: Livraria Classica Editora, 1907)

Quartim, P., 'A obrigação de procriar', A Batalha. Suplemento semanal ilustrado, 1 (1923), 3

Quiroule, P. [Joaquín Alejo Falconnet], 'Sobre Malthusianismo', La Protesta, 1581 (1909), 1

Ramus, P., ‘¿Existe en el hombre una maldad originaria?', La Protesta, 4271 (1922), 2

Ramus, P., 'Une lettre de Pierre Ramus', La Voix Libertaire, 297 (1935), 1

Raposo, L., Esbôço crítico do neo-maltusianismo, offprint from Acção Médica, 40 (Lisbon: Imprensa Lucas \& $\left.C^{a}, 1946\right)$ 
'Rapport au Congrès libertaire de Paris, Septembre 1900', flyer in Régénération, 2 (1900)

Raul, 'Decadencia del anarquismo. I', Natura, 3 (1903), 117-120

Raul, 'Decadencia del anarquismo. II', Natura, 9 (1904), 133-136

Raul, 'Decadencia del anarquismo. III y último', Natura, 10 (1905), 148-149

Relgis, E. 'Humanitarismo y Eugenismo', Estudios, 122 (1933), 14-17

Relgis, E. 'Humanitarismo y Eugenismo', Estudios, 123 (1933), 30-33

Relgis, E. 'Humanitarismo y Eugenismo', Estudios, 124 (1933), 18-21.

Relgis, E. 'La vaséctomie', La Grande Réforme, 35 (1934), 4

Relgis, E. Umanitarism și eugenism (Bucharest: Editura Vegetarianismul, 1934)

Relgis, E. Humanitarismo y Eugenismo (Toulouse: Ediciones Universo, 1950)

Reporter, 'J. J. Humphrey on eugenics', Freedom, new series, 49 (1934), 4

Ricard, [F.], 'Los hombres superiores', La Protesta, 2309 (1914), 2

Ricard, [F.], 'Determinismo y pesimismo', La Protesta, 2320 (1914), 1

Ricard, [F.], 'Esbozo de una filosofía de la perfección', La Protesta, 2445 (1915), 4-5

Ricard, F., ‘¿El hombre es bueno? El misticismo moderno’, Prometeo, 4 (1919), $10-12$

Richard, M., 'Puériculture', La Grande Réforme, 12 (1932), 3

Richet, C., Sélection humaine (Paris: Félix Alcan, 1919)

R[obin], P., 'Un procédé de stérilisation', Régénération, 8 (1905), 70

R[obin], P., 'Dégénérescence de l'espèce humaine. Causes et Remèdes', Régénération, 10 (1905), 86-87

R[obin], P., 'Les Mariages de Dégénérés', Régénération, 28 (1907), 245-246

Robin, P., 'À mes successeurs', Régénération. Organe de la Ligue de la Régénération Humaine, 1 (1900), 1-2

Robin, P., 'Ligue de la Régénération Humaine. Sommaire de conférences sur le néo-Malthusianisme', Régénération. Organe de la Ligue de la Régénération Humaine, 1 (1900), 5-6

Robin, P., Dégénérescence de l'espèce humaine. Causes et remèdes, 4th edn (Paris: Libertaire, 1909)

Rodrigo Bernal, M., 'El moderno neomalthusianismo', La Protesta, 2674 (1915), 2

Roué, P., 'Stérilisation légale', La Grande Réforme, 80 (1937), 6

Roussel, N., 'Féminisme et malthusianisme', Génération Consciente, 34 (1911), 1

Rout, E. A., 'Healthy Sex-Love', The Spur, 12 (1920), 75

Ruiz, A., 'El problema de la población', La Protesta, 1550 (1909), 2

S. M., 'La mujer y la familia', La Protesta Humana, 1 (1897), 1-2

St-John, A., 'Herbert Spencer', L'Ère Nouvelle, 27 (1904), 132-133

Samblancat, A., 'A la regeneración por la escuela', La Protesta, 4269 (1922), 2

Samblancat, A., 'Crónicas de España. Contra el lapinismo', La Protesta, 4484 (1923), 2

Sanger, M. H., 'Birth Control in America', Freedom, 315 (1915), 51

Scalise, J., 'La unión libre', Ideas, 89 (1923), 3

Schumacher, L.-M., 'La Sélection humaine', Régénération. Organe de la Ligue de la Régénération Humaine, 18 (1902), 119-120

Schuster, E., Campbell, H. and Mackintosh, J. S., 'Discussion on "Eugenics", The British Medical Journal, 2:2744 (1913), 223-231

Senhouse, T., 'Sexual Morality and the Church', Freedom, 367 (1919), 69 
Spencer, H., A Theory of Population, Deduced from the General Law of Animal Fertility (London: G. Woodfall, no date)

Spencer, H., 'The Factors of Organic Evolution. I', The Nineteenth Century and After: A Monthly Review, 19:110 (1886), 570-589

Spencer, H., 'The Factors of Organic Evolution. Concluded', The Nineteenth Century and After: A Monthly Review, 19:111 (1886), 749-770

Sylla, 'Sobre o Neo-Maltusianismo', Germinal, 40 (1904), 1

Tcherkessof, W., 'Pages d'histoire socialiste', Les Temps Nouveaux, 1:40 (1896), 2-3

Teixeira Junior, J. J., Mulheres, Não Procriéis! (Lisbon: Biblioteca de Escritores Jovens, 1911)

Tensin, J. de, 'Darwin et la Descendance de l'Homme', L'Anarchie, 4:205 (1909), 3

Toulouse, [E.], 'De la educación. El carácter', La Protesta, 2554 (1915), 3

Toulouse, [E.], 'De la educación. Perversiones del Instinto', La Protesta, 2588 (1915), 2

Um estudante da EIAD, 'Contra o fascismo que impera em Portugal', A Batalha, 1 (1934), 3

Un Médico Rural [Isaac Puente], 'A modo de programa', Estudios, 94 (1931), 1-3

Urales, F., 'La evolución de la filosofía en España', La Revista Blanca, 94 (1902), 673-677

Uxia, P., 'El atavismo es la negación de la libertad', La Protesta, 2228 (1914), 1

Vaz, Â., Neo-Malthusianismo: These inangural apresentada á Escola MedicoCirurgica do Porto (Oporto: Tip. da Empreza Litteraria e Typographica, 1902).

Villarruel, S., 'Más sobre la perfección individual', Ideas, 124 (1924), 3

Wakeman, J., 'Sexual Morality and the Church', Freedom, 366 (1919), 62

Witcop, R., 'Contributions to Sex Knowledge', The Spur, 7 (1919), 27

XXX, 'La Eugenesia en América', Salud y Fuerza, 59 (1914), 361-363

Zeno, L. O., 'El eugenismo tomado por las patas', Prometeo, 4 (1919), 4-6

Zeno, L. O., 'Medicina social e individual. VIII', La Protesta, 3713 (1919), 2-3

\section{Secondary sources}

Anon., 'Introduction', in Greta Jones and Robert A. Peel (eds), Herbert Spencer: The Intellectual Legacy (London: The Galton Institute, 2004), ix-xv

Abelló i Güell, T., 'El Neomalthusianisme a Catalunya. Lluís Bulffi i la "Liga de la Regeneración Humana”' (Dissertation, University of Barcelona, 1979)

Accampo, E., Blessed Motherhood, Bitter Fruit: Nelly Roussel and the Politics of Female Pain in Third Republic France (Baltimore, MD: Johns Hopkins University Press, 2006)

Ackelsberg, M. A., Free Women of Spain: Anarchism and the Struggle for the Emancipation of Women (Oakland, CA/Edinburgh: AK Press, 2005 [1991])

Adams, M. B., The Wellborn Science: Eugenics in Germany, France, Brazil, and Russia (Oxford: Oxford University Press, 1990)

Adams, M. S., Kropotkin, Read, and the Intellectual History of British Anarchism: Between Reason and Romanticism (Basingstoke: Palgrave Macmillan, 2015) 
Adams, M. S., 'Formulating an Anarchist Sociology: Peter Kropotkin's Reading of Herbert Spencer', Journal of the History of Ideas, 77:1 (2016), 49-73

Ahmed, S., Willful Subjects (Durham, NC: Duke University Press, 2014) Aisa, F., La cultura anarquista a Catalunya (Barcelona: Edicions de 1984, 2006)

Allen, G., 'From Eugenics to Population Control: The Work of Raymond Pearl', Science for the People, no number (July/August 1980), 22-28

Almaça, C., 'Neo-Lamarckism in Portugal', Asclepio, 52:2 (2000), 85-98

Álvarez Junco, J., La ideología política del anarquismo español (1868-1910) (Madrid: Siglo XXI, 1991 [1976])

Álvarez Peláez, R., 'Origen y desarrollo de la eugenesia en España', in J. M. Sánchez Ron (ed.), Ciencia y Sociedad en España: de la Ilustración a la Guerra Civil (Madrid: El Arquero/CSIC, 1988), pp. 179-204

Álvarez Peláez, R., 'Eugenesia y darwinismo social en el pensamiento anarquista', in B. Hofmann, P. Joan i Tous and M. Tietz (eds), El anarquismo español y sus tradiciones culturales (Frankfurt am Main/Madrid: Vervuert/Iberoamericana, 1995), pp. 29-40

Aresti, N., 'La nueva mujer sexual y el varón domesticado: el movimiento liberal para la reforma de la sexualidad (1920-1936)', Arenal. Revista de Historia de las Mujeres, 9:1 (2002), 125-150

Avrich, P., Anarchist Voices: An Oral History of Anarchism in America (Princeton, NJ: Princeton University Press, 1996)

Bach Jensen, R., 'The International Anti-Anarchist Conference of 1898 and the Origins of Interpol', Journal of Contemporary History, 16:2 (1981), 323-347

Bach Jensen, R., 'The United States, International Policing and the War against Anarchist Terrorism, 1900-1914', Terrorism and Political Violence, 13:1 (2001), 15-46

Baer, J. A., Anarchist Immigrants in Spain and Argentina (Urbana, IL and Chicago/ Springfield, MA: University of Illinois Press, 2015)

Baker, G. J., 'Christianity and Eugenics: The Place of Religion in the British Eugenics Education Society and the American Eugenics Society, c. 1907-1940', Social History of Medicine, 27:2 (2014), 281-302

Bantman, C., 'From Trade Unionism to Syndicalisme Révolutionnaire to Syndicalism: The British Origins of French Syndicalism', in D. Berry and C. Bantman (eds), New Perspectives on Anarchism, Labour and Syndicalism: The Individual, the National and the Transnational (Newcastle: Cambridge Scholars Press, 2010), pp. 126-140

Bantman, C., The French Anarchists in London, 1880-1914: Exile and Transnationalism in the First Globalisation (Liverpool: Liverpool University Press, 2013).

Bantman, C., 'Jean Grave and French Anarchism: A Relational Approach (1870s1914)', International Review of Social History, 62:3 (2017), 451-477

Bantman, C. and Altena, B. (eds), Reassessing the Transnational Turn: Scales of Analysis in Anarchist and Syndicalist Studies (New York/London: Routledge, 2015)

Barrancos, D., 'Anarquismo y sexualidad', in Diego Armus (ed.), Mundo urbano y cultura popular: estudios de historia social argentino (Buenos Aires: Editorial Sudamericana, 1990), pp. 16-37 
Barrett, D. and Kurzman, C., 'Globalizing Social Movement Theory: The Case of Eugenics', Theory and Society, 33:5 (2004), 487-527

Barrio Alonso, A., 'Anarquismo y "cuestión social”, Historia Contemporánea, 29 (2005), 759-784

Basalla, G., 'The Spread of Western Science', Science, 3775:156 (1967), 611-622

Bashford, A., 'Internationalism, Cosmopolitanism, and Eugenics', in Alison Bashford and Philippa Austin (eds), The Oxford Handbook of the History of Eugenics (Oxford: Oxford University Press, 2010), pp. 154-172

Bennett, J., 'Reflections of the Writing of Comparative and Transnational Labour History', History Compass, 7:2 (2009), 376-394

Berlin, I., 'Two Concepts of Liberty', in Isaiah Berlin (ed.), Four Essays on Liberty (London/Oxford/New York: Oxford University Press, 1969), pp. 118-172

Berlivet, A., 'A Laboratory for Latin Eugenics: The Italian Committee for the Study of Population Problems and the International Circulation of Eugenic Knowledge, 1920s-1940s', História, Ciências, Saúde - Manguinhos, 23:supplement (2016), $51-72$

Berry, D., A History of the French Anarchist Movement, 1917 to 1945 (Oakland, CA/Edinburgh: AK Press, 2009)

Berry, D. and Bantman, C. (eds), New Perspectives on Anarchism, Labour and Syndicalism: The Individual, the National and the Transnational (Newcastle: Cambridge Scholars Press, 2010)

Blacker, C. P., 'Voluntary Sterilization: The Last Sixty Years', The Eugenics Review, 54:1 (1962), 9-23

Blom, P., The Vertigo Years: Change and Culture in the West, 1900-1914 (New York: Basic Books, 2008)

Bookchin, M., Re-enchanting Humanity: A Defense of the Human Spirit against Anti-humanism, Misanthropy, Mysticism and Primitivism (London/New York: Cassell, 1995)

Bosc, O., 'Eugénisme et socialisme en Italie autour de 1900. Robert Michels et l' "éducation sentimentale des masses", Mil neuf cent, 18 (2000), 81-108

Bourdieu, P., 'Sur le pouvoir symbolique', Annales: Économies, Sociétés, Civilisations, 32:3 (1977), 405-411

Bowler, P. J., 'E. W. MacBride's Lamarckian Eugenics and Its Implications for the Social Construction of Scientific Knowledge', Annals of Science, 41 (1984), $245-260$

Bowler, P. J., The Non-Darwinian Revolution: Reinterpreting a Historical Myth (Baltimore, MD/London: Johns Hopkins University Press, 1988)

Bowler, P. J., The Invention of Progress: The Victorians and the Past (Oxford/ Cambridge, MA: Basil Blackwell, 1989)

Bowler, P. J., The Mendelian Revolution: The Emergence of Hereditarian Concepts in Modern Science and Society (London: The Athlone Press, 1989)

Bowler, P. J., Darwin Deleted: Imagining a World without Darwin (Chicago/ London: University of Chicago Press, 2013)

Brauer, F., 'Introduction. Making Eugenic Bodies Delectable: Art, "Biopower" and "Scientia Sexualis", in F. Brauer and A. Callen (eds), Art, Sex and Eugenics: Corpus Delecti (Aldershot/Burlington, VT: Ashgate, 2008), pp. 1-34 
Broberg, G. and Roll-Hansen, N., Eugenics and the Welfare State: Sterilization Policy in Denmark, Sweden, Norway, and Finland (East Lansing, MI: Michigan State University Press, 1996)

Brown, L. S., The Politics of Individualism: Liberalism, Liberal Feminism and Anarchism (Montreal/New York/London: Black Rose Books, 1993)

Burdett, C., 'Introduction: Eugenics Old and New', New Formations, 60 (2007), $7-12$

Cahm, C., Kropotkin and the Rise of Revolutionary Anarchism, 1872-1886 (Cambridge: Cambridge University Press, 1989)

Call, L., Postmodern Anarchism (Lanham, MD/Oxford: Lexington Books, 2002)

Campos Marín, R., Martínez Pérez, J. and Huertas García-Alejo, R., Los ilegales de la naturaleza. Medicina y degeneracionismo en la España de la Restauración, 1876-1923 (Madrid: CSIC, 2000)

Capellán de Miguel, G., La España armónica. El proyecto del krausismo español para una sociedad en conflicto (Madrid: Biblioteca Nueva, 2006)

Chamberlin, J. E. and Gilman, S. L. (eds), Degeneration: The Dark Side of Progress (New York/Guildford: Columbia University Press, 1985)

Chambers, D. W., 'Locality and Science: Myths of Centre and Periphery', in A. Lafuente, A. Elena and M. L. Ortega (eds), Mundialización de la ciencia y cultura nacional (Madrid: Doce Calles, 1993), pp. 605-618

Charnley, B., and Radick, G., 'Intellectual Property, Plant Breeding and the Making of Mendelian Genetics', Studies in History and Philosophy of Science, 44:2 (2013), 222-233

Childs, D. J., Modernism and Eugenics: Woolf, Eliot, Yeats and the Culture of Degeneration (Cambridge: Cambridge University Press, 2001)

Clark, J. P., and Martin, C. (eds), Anarchy, Geography, Modernity: The Radical Social Thought of Elisée Reclus (Lanham, MD: Lexington Books, 2004)

Cleminson, R., Anarchism, Science and Sex: Eugenics in Eastern Spain, 19001937 (Oxford/Bern: Peter Lang, 2000)

Cleminson, R., “'A Century of Civilization under the Influence of Eugenics”: Dr. Enrique Diego Madrazo, Socialism and Scientific Progress', Dynamis, 26 (2006), 221-251

Cleminson, R., 'The Construction of Masculinity in the Spanish Labour Movement: A Study of the Revista Blanca (1923-36)', International Journal of Iberian Studies, 24:3 (2012), 210-217

Cleminson, R., Catholicism, Race and Empire: Eugenics in Portugal, 1900-1950 (New York/Budapest: Central European University Press, 2014)

Cleminson, R., 'Eugenics, Sex Reform, Religion and Anarchism in Portugal', The Journal of Religious History, Literature and Culture, 4:2 (2018), 61-84

CNT, El Congreso Confederal de Zaragoza (Madrid: Zero ZXY, 1978)

Cohn, J. and Jun, N., 'Introduction', Anarchist Developments in Cultural Studies, 1 (2015), iii-viii

Confino, M., Anarchistes en exil. Correspondance inédite de Pierre Kropotkine à Marie Goldsmith, 1897-1917 (Paris: Institut d'Études Slaves, 1995)

Connelly, M., 'Seeing Beyond the State: The Population Control Movement and the Problem of Sovereignty', Past and Present, 193 (2006), 197-233 
Cova, A., Féminismes et néo-malthusianismes sous la IIÌ République: «La liberté de la maternité» (Paris: L'Harmattan, 2011)

Cova, A., 'Feminisms and Associativism: The National Councils of Women in France and Portugal, a Comparative Historical Approach, 1889-1939', Women's History Review, 22:1 (2013), 19-30

Crowder, G., Classical Anarchism: The Political Thought of Godwin, Proudhon, Bakunin, and Kropotkin (Oxford: Clarendon Press, 1991)

Darlington, R., 'Syndicalism and the Influence of Anarchism in France, Italy and Spain', Anarchist Studies, 17:2 (2009), 29-54

Dean, M., Critical and Effective Histories: Foucault's Methods and Historical Sociology (London/New York: Routledge, 1994)

Dean, M., Governmentality: Power and Rule in Modern Society (London: Sage, 1999)

Dean, M., The Signature of Power: Sovereignty, Governmentality and Biopolitics (London: Sage, 2013)

De Luca, V. and Praz, A.-F., 'The Emergence of Sex Education: A Franco-Swiss Comparison, 1900-1930', Journal of the History of Sexuality, 24:1 (2015), 46-74

Demeulenaere-Douyère, C., Paul Robin (1837-1912). Un militant de la liberté et du bonheur (Paris: Publisud, 1994)

Díaz, C. (ed.), Cesare Lombroso - Ricardo Mella. Los Anarquistas (Madrid: Ediciones Júcar, 1978)

Díez, X., Utopia sexual a la premsa anarquista de Catalunya. La revista ÉticaIniciales (1927-1937) (Lleida: Pagès editors, 2001)

Dos Santos, R.A., 'Intelectuales y redes eugénicas de América Latina. Relaciones entre Brasil y Argentina a través de Renato Kehl y Víctor Delfino', in Marisa Miranda and Gustavo Vallejo (eds), Una historia de la eugenesia. Argentina y las redes biopolíticas internacionales 1912-1945 (Buenos Aires: Editorial Biblos, 2012), pp. 65-95

Drouard, A., 'Aux origines de l'eugénisme en France: Le néo-malthusianisme (1896-1914)', Population, 2 (1992), 435-460

Duarte, D., 'Everyday forms of Utopia: Anarchism and Neo-Malthusianism in Portugal in the Early Twentieth Century', in Francisco Bethencourt (ed.), Utopia in Portugal, Brazil and Lusophone African Countries (Oxford: Peter Lang, 2015), pp. 251-273

Etkind, A., 'Beyond Eugenics: The Forgotten Scandal of Hybridizing Humans and Apes', Studies in History and Philosophy of Science. Part C: Studies in History and Philosophy of Biological and Biomedical Sciences, 39:2 (2008), 205-210

Evans, R. J., 'In Search of German Social Darwinism: The History and Historiography of a Concept', in Manfred Berg and Geoffrey Cocks (eds), Medicine and Modernity: Public Health and Medical Care in Nineteenth-and Twentieth-Century Germany (Cambridge: Cambridge University Press, 1997), pp. 55-79

Febvre, L., Autour de l'Heptaméron. Amour sacré, amour profane (Paris: Gallimard, 1944)

Fleming, M., The Anarchist Way to Socialism: Élisée Reclus and NineteenthCentury European Anarchism (London: Croom Helm, 1979) 
Flunser Pimentel, I., 'Women's Organisations and Imperial Ideology under the Estado Novo', Portuguese Studies, 18 (2002), 121-131

Foucault, M., The History of Sexuality, Vol. I, An Introduction (Harmondsworth: Penguin, 1990)

Foucault, M., 'Polemics, Politics, and Problematizations: An Interview with Michel Foucault', in Paul Rabinow (ed.), Michel Foucault: The Essential Works. Vol I. Ethics (London: Allen Lane, 1997), pp. 111-119

Francisco, J., Páginas do historial cegetista (Lisbon: Editorial Sementeira, 1983)

Freeden, M., 'Eugenics and Progressive Thought: A Study in Ideological Affinity', The Historical Journal, 22:3 (1979), 645-671

Freeman, D., et al., 'The Evolutionary Theories of Charles Darwin and Herbert Spencer', Current Anthropology, 15:3 (1974), 211-237

Freire, J., 'Ideologia, ofício e práticas sociais: O anarquismo e o operariado em Portugal 1900-1940' (Doctoral thesis, University of Lisbon, 1988)

Freire, J., Anarquistas e operários. Ideologia, ofício e práticas sociais: o anarquismo e o operariado em Portugal, 1900-1940 (Oporto: Edições Afrontamento, 1992)

Freire, J. and Lousada, M. A., 'O neomalthusianismo na propaganda libertária', Análise Social, 18:72-73-74 (1982), 1367-1397

Freire, J. and Lousada, M. A. (eds), Greve de Ventres! Para a história do movimento neomalthusiano em Portugal: em favor de um autocontrolo da natalidade (Lisbon: Edições Colibri, 2012)

Galera Gómez, A., 'La antropología criminal frente al anarquismo español', in Bert Hofmann, Pere Joan i Tous and Manfred Tietz (eds), El anarquismo español y sus tradiciones culturales (Frankfurt/Madrid: Vervuert/Iberoamericana, 1995), pp. 109-120

Gerodetti, N., 'Eugenic Family Politics and Social Democrats: "Positive” Eugenics and Marriage Advice Bureaus', Journal of Historical Sociology, 19:3 (2006), 217-244

Girón, A., 'Metáforas finiseculares del declive biológico: degeneración y revolución en el anarquismo español (1872-1914)', Asclepio, 51:1 (1999), 247-273

Girón Sierra, A., 'La economía moral de la naturaleza: darwinismo y lucha por la existencia en el anarquismo español (1882-1914)', in Thomas F. Glick, Rosaura Ruiz and Miguel Ángel Puig-Samper (eds), El darwinismo en España e Iberoamérica (Madrid: Universidad Nacional Autónoma de México/CSIC/ Ediciones Doce Calles, 1999), pp. 249-263

Girón Sierra, A., En la mesa con Darwin. Evolución y revolución en el movimiento libertario en España (1869-1914) (Madrid: CSIC, 2005)

Girón Sierra, A., 'Piotr Kropotkin contra la eugenesia: siete intensos minutos', in Gustavo Vallejo and Marisa Miranda (eds), Derivas de Darwin: cultura y política en clave biológica (Buenos Aires: Siglo XXI, 2010), pp. 119-142

Gissis, S. B. and Jablonka, E. (eds), Transformations of Lamarckism: From Subtle Fluids to Molecular Biology (Cambridge, MA/London: MIT Press, 2011)

Glass, D. V., 'Malthus and the Limitation of Population Growth', in D. V. Glass (ed.), Introduction to Malthus (London: Watts, 1953)

Godwin, W., Of Population: An Inquiry Examining the Power of Increase in the Numbers of Mankind (New York: Augustus M. Kelley, Bookseller, 1964 [1820])

Goldman, E., 'Marriage and Love', in Richard Drinnon (ed.), Emma Goldman: Anarchism and Other Essays (New York: Dover, 1969), pp. 227-239 
Goodway, D., 'Freedom, 1886-2014: An Appreciation', History Workshop Journal, 79 (2015), 233-242

Gómez Muller, A., Anarquismo y anarcosindicalismo en América Latina. Colombia, Brasil, Argentina, México (Medellín: La Carreta Editores, 2009)

Gordon, F., The Integral Feminist: Madeleine Pelletier, 1874-1939 (Cambridge: Polity Press, 1990)

Gordon, U., Anarchy Alive! Anti-Authoritarian Politics from Practice to Theory (London/Ann Arbor, MI: Pluto Press, 2008)

Gould, S. J., Ontogeny and Phylogeny (Cambridge, MA: Belknap Press of Harvard University Press, 1977)

Gould, S. J., 'Kropotkin Was No Crackpot', in Stephen Jay Gould (ed.), Bully for Brontosaurus: Reflections in Natural History (London: Vintage, 1991), pp. 325-339

Goyens, T., 'Social Space and the Practice of Anarchist History', Rethinking History: The Journal of Theory and Practice, 13:4 (2009), 439-457

Graham, L. R., 'Science and Values: The Eugenics Movement in Germany and Russia in the 1920s', The American Historical Review, 82:5 (1977), 1133-1164

Grazia, V. de, How Fascism Ruled Women: Italy, 1922-1945 (Berkeley and Los Angeles, CA/Oxford: University of California Press, 1992)

Guereña, J.-L., La prostitución en la España contemporánea (Madrid: Marcial Pons, 2003)

Guerrand, R.-H. and Ronsin, F., Jeanne Humbert et la lutte pour le contrôle des naissances (Paris: Spartacus, 2001)

Haas, P. M., 'Introduction: Epistemic Communities and International Policy Coordination', International Organization, 46:1 (1992), 1-35

Hall, L. A., 'Malthusian Mutations: The Changing Politics and Moral Meanings of Birth Control in Britain', in Brian Dolan (ed.), Malthus, Medicine, and Morality: 'Malthusianism' after 1798 (Amsterdam/Atlanta, GA: Rodopi, 2000), pp. 141-163

Hall, L. A., 'Eugenics, Sex and the State: Some Introductory Remarks', Studies in History and Philosophy of Science. Part C: Studies in History and Philosophy of Biological and Biomedical Sciences, 39:2 (2008), 177-180

Harris, R., Murders and Madness: Medicine, Law and Society in the fin de siecle (Oxford: Clarendon Press, 1989)

Hayden, W., Evolutionary Rhetoric: Sex, Science, and Free Love in NineteenthCentury Feminism (Carbondale and Edwardsville, IL: Southern Illinois University Press, 2013)

Hemmings, C., Considering Emma Goldman: Feminist Political Ambivalence and the Imaginative Archive (Durham/London: Duke University Press, 2018)

Herbert, S., 'Darwin, Malthus, and Selection', Journal of the History of Biology, 4:1 (1971), 209-218

Hobsbawm, E., The Age of Empire 1875-1914 (London: Weidenfeld and Nicolson, 1995)

Holton, R. J., British Syndicalism, 1900-1914 (London: Pluto Press, 1975)

James, P., Population Malthus: His Life and Times (London: Routledge and Kegan Paul, 1979)

Jiménez, I. and Molero, J., 'Per una "sanitat proletària”. L’Organització Sanitària Obrera de la Confederació Nacional del Treball (CNT) a la Barcelona republicana 
(1935-1936)', Gimbernat. Revista Catalana d'Història de la Medicina i de la Ciència, 39 (2003), 211-221

Jiménez-Lucena, I. and Molero-Mesa, J., 'Good Birth and Good Living. The (De) medicalizing Key to Sexual Reform in the Anarchist Media of Inter-war Spain', International Journal of Iberian Studies, 24:3 (2012), 219-241

Jiménez-Lucena, I. and Molero-Mesa, J., 'Una dialógica desestabilizadora del orden social y sexual: el médico argentino Juan Lazarte en la revista anarquista Estudios (1932-1936)', Asclepio, 66:2 (2014), online at http://dx.doi.org/10 .3989/asclepio.2014.20 (accessed 16 July 2018)

Joyce, P., Visions of the People: Industrial England the Question of Class, 1848 1914 (Cambridge: Cambridge University Press, 1991)

Joyce, P., 'Introduction', in Patrick Joyce (ed.), The Social in Question: New Bearings in History and the Social Sciences (London/New York: Routledge, 2002), pp. 1-18

Joyce, P., (ed.), The Social in Question: New Bearings in History and the Social Sciences (London/New York: Routledge, 2002)

Jun, N., Anarchism and Political Modernity (New York/London: Continuum, 2012)

Kerr, A. and Shakespeare, T., Genetic Politics: From Eugenics to Genome (Cheltenham: New Clarion Press, 2002)

Kevles, D., In the Name of Eugenics: Genetics and the Uses of Human Heredity (New York: Knopf, 1985)

Kinna, R., 'Kropotkin's Theory of Mutual Aid in Historical Context', International Review of Social History, 40 (1995), 259-283

Knorr Cetina, K., Epistemic Cultures: How the Sciences make Knowledge (Cambridge, MA: Harvard University Press, 1999)

Koch, A. M., 'Poststructuralism and the Epistemological Basis of Anarchism', Philosophy of the Social Sciences, 23:3 (1993), 327-351

Koch, L., 'The Meaning of Eugenics: Reflections on the Government of Genetic Knowledge in the Past and the Present', Science in Context, 17:3 (2004), 315-331

Kolovou, E. and Karageorgakis, S., 'Free from Nature or Free Nature? An Anarchist Critique of Transhumanism', in N. J. Jun and S. Wahl (eds), New Perspectives on Anarchism (Lanham, MD/Plymouth: Lexington Books, 2010), pp. 315-332

Kropotkin, P., 'Editor's Introduction', in P. Avrich (ed.), Mutual Aid: A Factor of Evolution (London: Allen Lane The Penguin Press, 1972), pp. 1-10

Kropotkin, P., Act for Yourselves (London: Freedom Press, 1988)

Kühl, S., For the Betterment of the Race: The Rise and Fall of the International Movement for Eugenics and Racial Hygiene, trans. Lawrence Schofer (New York: Palgrave Macmillan, 2013)

Kuhn, G., 'Anarchism, Postmodernity, and Poststructuralism', in Randall Amster et al. (eds), Contemporary Anarchist Studies: An Introductory Anthology of Anarchy in the Academy (London/New York: Routledge, 2009), pp. 18-25

Laforcade, G. de and Shaffer, K. (eds), In Defiance of Boundaries: Anarchism in Latin American History (Gainesville, FL: University Press of Florida, 2015) 
Ledesma Prietto, N. F., 'Eugenesia y Revolución Sexual. El discurso médico anarquista sobre el control de la natalidad, la maternidad y el placer sexual. Argentina, 1931-1951' (Doctoral dissertation, University of La Plata, 2014)

Ledesma Prietto, N. and Manzoni, G., 'Anarquistas, médicos y homosexualidad. Límites de un discurso revolucionario (Argentina, 1930-1940)', La Brecha. Revista Anarquista de Historia y Ciencias Sociales, 4 (2017), 17-27

Levins, R. and Lewontin, R., 'The Problem of Lysenkoism', in Richard Levins and Richard Lewontin, The Dialectical Biologist (Cambridge, MA: Harvard University Press, 1985), pp. 163-196

Levy, C., 'The Rooted Cosmopolitan: Errico Malatesta, Syndicalism, Transnationalism and the International Labour Movement', in David Berry and Constance Bantman (eds), New Perspectives on Anarchism, Labour and Syndicalism: The Individual, the National and the Transnational (Newcastle: Cambridge Scholars Press, 2010), pp. 61-79

Lida, C. E., 'Agrarian Anarchism in Andalusia: Documents on the Mano Negra', International Review of Social History, 14:3 (1969), 315-352

Litvak, L., Musa libertaria. Arte, literatura y vida cultural del anarquismo español (1880-1913) (Barcelona: Antonio Bosch, 1981)

Lucassen, L., 'A Brave New World: The Left, Social Engineering, and Eugenics in Twentieth-Century Europe', International Review of Social History, 55:2 (2010), 265-296

Macrakis, K., Surviving the Swastika: Scientific Research in Nazi Germany (New York/Oxford: Oxford University Press, 1993)

Maitron, F., Le mouvement anarchiste en France, 2 vols. (Paris: François Maspero, 1975)

Marrus, M. R. and Paxton, R., Vichy France and the Jews (New York: Basic Books, 1981)

Marshall, P., Demanding the Impossible: A History of Anarchism (London: HarperCollins, 1992)

Martí, J. V. and Rey, A., Antología de textos de Félix Martí Ibáñez (Valencia: Biblioteca Valenciana, 2004)

Martí Boscà, J. V. and Rey González, A., 'El degeneracionismo en el pensamiento universitario anarquista español (1923-1939)', Ciencia y academia. IX Congreso Internacional de Historia de las universidades hispánicas (Valencia, septiembre 2005), vol. II (Valencia: Universitat de València, 2008), pp. 43-60

Martí Boscà, J. V. and Rey González, A., 'Félix Martí Ibáñez (Cartagena, 1911New York, 1972)', Revista de Salud Ambiental, 17:2 (2017), 208-216

Martin, T., 'Anarchism and the Question of Human Nature', Social Anarchism, 37 (2006), available at www.socialanarchism.org/mod/magazine/display/128/i ndex.php (accessed 22 January 2016)

Masjuan, E., La ecología humana en el anarquismo ibérico: urbanismo 'orgánico' o ecológico, neomaltusianismo y naturismo social (Barcelona: Icaria, 2000)

May, T., 'Is Post-Structuralist Political Theory Anarchist?', Philosophy and Social Criticism, 15:2 (1989), 167-182

May, T., The Political Philosophy of Poststructuralist Anarchism (University Park, PA: Pennsylvania University Press, 1994) 
May, T., 'Anarchism from Foucault to Rancière', in Randall Amster et al (eds), Contemporary Anarchist Studies: An Introductory Anthology of Anarchy in the Academy (London/New York: Routledge, 2009), pp. 11-25

May, T., 'Introduction', in Nathan J. Jun and Shane Wahl (eds), New Perspectives on Anarchism (Lanham, MD/Plymouth: Lexington Books, 2010), pp. 1-5

Mayr, E., The Growth of Biological Thought: Diversity, Evolution, and Inheritance (Cambridge, MA/London: The Belknap Press, 1982)

Mazumdar, P. M. H., Eugenics, Human Genetics and Human Failings: The Eugenics Society, Its Sources and Its Critics in Britain (London/New York: Routledge, 1992)

McKay, I., Mutual Aid: An Introduction and Evaluation (Edinburgh: AK Press, 2011)

McLaren, A., Sexuality and Social Order: The Debate over the Fertility of Women and Workers in France, 1770-1920 (London: Holmes and Meier, 1983)

McLaren, A., 'Sex Radicalism in the Canadian Pacific Northwest, 1890-1920', Journal of the History of Sexuality, 2:4 (1992), 527-546

McLaren, A., Twentieth-Century Sexuality: A History (Oxford/Malden, MA: Blackwell, 1999)

McLaren, A., 'Reproduction and Revolution: Paul Robin and Neo-Malthusianism in France', in B. Dolan (ed.), Malthus, Medicine, and Morality: 'Malthusianism' after 1798 (Amsterdam/Atlanta, GA: Rodopi, 2000), pp. 165-188

Medina, J., 'Toward a Foucaultian Epistemology of Resistance: CounterMemory, Epistemic Friction, and Guerrilla Pluralism', Foucault Studies, 12 (2011), 9-35

Miranda, M. and Vallejo, G. (eds), Una historia de la eugenesia: Argentina y las redes biopoliticas internacionales 1912-1945 (Buenos Aires: Editorial Biblos, 2012)

Molero-Mesa, J. and Jiménez-Lucena, I., “Brazo y cerebro”: Las dinámicas de inclusión-exclusión en torno a la profesión médica y el anarcosindicalismo español en el primer tercio del siglo XX', Dynamis, 33:1 (2013), 19-41

Moore, G., Nietzsche, Biology, and Metaphor (Cambridge/New York: Cambridge University Press, 2002)

Morales Muñoz, M., Cultura e ideología en el anarquismo español (1870-1910) (Malaga: Diputación de Málaga, 2002)

Morland, D., Demanding the Impossible? Human Nature and Politics in NineteenthCentury Social Anarchism (London/Washington DC: Cassell, 1997)

Mottier, V. and Gerodetti, N., 'Eugenics and Social Democracy: Or, How the European Left Tried to Eliminate the "Weeds" From Its National Gardens', New Formations, 60 (2007), 35-49

Nadal, J., Bautismos, deposorios y entierros: Estudios de historia demográfica (Barcelona: Ariel, 1992)

Nash, M., 'Mujeres Libres': España 1936-1939 (Barcelona: Tusquets, 1975)

Nash, M., 'L'avortament legal a Catalunya. Una experiència fracassada', L'Avenç, 58 (1983), 20-26

Nash, M., 'El neomalthusianismo anarquista y los conocimientos populares sobre el control de la natalidad', in Mary Nash (ed.), Presencia y protagonismo. Aspectos de la historia de la mujer (Barcelona: Ediciones del Serbal, 1984), pp. $309-340$ 
Navarro Navarro, F. J., 'El paraíso de la razón'. La revista Estudios (1928-1937) y el mundo cultural anarquista (Valencia: Edicions Alfons el Magnànim, 1997)

Navarro Navarro, J., 'Sexualidad, reproducción y cultura obrera revolucionaria en España: La revista Orto (1932-1934)', Arbor, revista de Ciencia, Pensamiento y Cultura,190:769(2014), available online at http://arbor.revistas.csic.es/index.php /arbor/article/view/1977/2350 (accessed 20 July 2018)

Nye, R. A., Crime, Madness, and Politics in Modern France: The Medical Concept of National Decline (Princeton, NJ: Princeton University Press, 1984)

Olin, D., Paradox (Chesham: Acumen, 2003)

Olson, R., Science and Scientism in Nineteenth-Century Europe (Urbana, IL: University of Illinois Press, 2008)

Ordover, N., American Eugenics: Race, Queer Anatomy, and the Science of Nationalism (Minneapolis, MN/London: University of Minnesota Press, 2003)

Orgel, M. N., 'Excursionismo: An Anthropological and Anarchist Methodology for Exploring the Past', Contemporary Justice Review, 5:1 (2002), 35-45

Overy, R., 'Eugenics, Sex and the State: An Afterword', Studies in History and Philosophy of Science. Part C: Studies in History and Philosophy of Biological and Biomedical Sciences, 39:2 (2008), 270-272

Padovan, D., Saperi strategici: le scienze sociali e la formazione dello spazio pubblico italiano fra le due guerre mondiali (Milan: Franco Angeli, 1999)

Parsons, D., 'Neo-Malthusianism, Anarchism and Resistance: World View and the Limits of Acceptance in Barcelona (1904-1914)', Entremons. UPF Journal of World History, 4 (2012), 1-18

Paul, D., 'Eugenics and the Left', Journal of the History of Ideas, 45 (1984), $567-590$

Paul, D. B. and Moore, J., 'The Darwinian Context: Evolution and Inheritance', in Alison Bashford and Philippa Austin (eds), The Oxford Handbook of the History of Eugenics (Oxford: Oxford University Press, 2010), pp. 27-42

Peel, J. D. Y., Herbert Spencer: The Evolution of a Sociologist (London: Heinemann, 1971)

Peeters, E., 'Authenticity and Asceticism: Discourse and Performance in Nude Culture and Health Reform in Belgium, 1920-1940', Journal of the History of Sexuality, 15:3 (2006), 432-461

Pereira, A. L., Darwin em Portugal. Filosofia. História. Engenharia Social (18651914) (Coimbra: Livraria Almedina, 2001)

Pichot, A., The Pure Society: From Darwin to Hitler, trans. David Fernbach (London/New York: Verso, 2009)

Pick, D., 'The Faces of Anarchy: Lombroso and the Politics of Criminal Science in Post-Unification Italy', History Workshop Journal, 21 (1986), 60-86

Pick, D., Faces of Degeneration: A European Disorder, c. 1848-c.1918 (Cambridge: Cambridge University Press, 1989)

Pinar, S., 'The Emergence of Modern Genetics in Spain and the Effects of the Spanish Civil War (1936-1939) on Its Development', Journal of the History of Biology, 35:1 (2002), 111-148

Porter, D. (ed.), Vision on Fire: Emma Goldman on the Spanish Revolution (New Paltz, NY: Commonground Press, 1983)

Prasad, D., War Is a Crime against Humanity: The Story of the War Resisters' International (London: War Resisters' International, 2005) 
Proudhon, P., 'The Malthusians' (1848, trans. Benjamin Tucker), in I. McKay (ed.), Property is Theft! A Pierre-Joseph Proudhon Anthology (Edinburgh/Oakland, CA/Baltimore, MD: AK Press, 2011), pp. 353-358

Puig-Samper, M. A., Ruíz, R. and Galera, A. (eds), Evolucionismo y cultura. Darwinismo en Europa y Iberoamérica (Madrid: Junta de Extremadura/ Universidad Nacional Autónoma de México/Ediciones Doce Calles, 2002)

Purkiss, R., Democracy, Trade Unions and Political Violence in Spain: The Valencian Anarchist Movement, 1918-1936 (Brighton/Chicago/Toronto: Sussex Academic Press, 2011)

Quine, W. V., The Ways of Paradox and Other Essays (New York: Random House, 1966)

Quine, M. S., Population Politics in Twentieth-Century Europe: Fascist Dictatorships and Liberal Democracies (London: Routledge, 1995)

Quintais, L., 'Torrent of Madmen: The Language of Degeneration in Portuguese Psychiatry at the Close of the 19th Century', História, Ciências, Saúde Manguinhos, 15:2 (2008), 353-369

Radick, G., 'Other Histories, Other Biologies', in Anthony O'Hear (ed.), Philosophy, Biology and Life. Royal Institute of Philosophy Supplement 56 (Cambridge: Cambridge University Press, 2005), pp. 21-47

Rago, M., 'O anarquismo e a história', in Various Authors, Retratos de Foucault (Rio de Janeiro: Nau Editora, 2000), pp. 88-116

Redvaldsen, D., 'Eugenics, Socialists and the Labour Movement in Britain, 18651940', Historical Research, 90:250 (2017), 764-787

Renwick, C., British Sociology's Lost Biological Roots: A History of Futures Past (Blasingstoke: Palgrave Macmillan, 2012)

Richards, V. (ed.), Malatesta: His Life and Ideas (London: Freedom Press, 1984)

Rodrigues, E., História do Movimento Anarquista em Portugal (Florianópolis: Editora Insular, 1999)

Ronsin, F., La grève des ventres. Propagande néo-malthusienne et baisse de la natalité en France 19e $-20^{\mathrm{e}}$ siècles (Poitiers: Aubier Montaigne, 1980)

Rose, H. and Rose, S., 'Red Scientist: Two Strands from a Life in Three Colours', in Brenda Swann and Francis Aprahamian (eds), J. D. Bernal: A Life in Science and Politics (London/New York: Verso, 1999), pp. 132-159

Rosselló, J. M., La vuelta a la naturaleza. El pensamiento naturista hispano (18902000): naturismo libertario, trofología, vegetarismo naturista, vegetarismo social y librecultura (Barcelona: Virus, 2003)

Ruiz Gutiérrez, R., 'Darwin and Inheritance: The Influence of Prosper Lucas', Journal of the History of Biology, 42:4 (2009), 685-714

Russell, D., The Tamarisk Tree: My Quest for Liberty and Love (London: Virago, 1977)

Sánchez Blanco, L., 'Mujeres Libres en la Guerra Civil española. La capacitación cultural y profesional en la región de Cataluña', Historia Social y de la Educación, 6:3 (2017), 290-313

Santana, E., História de um atentado: O atentado a Salazar (Mem Martins: Forum, 1976)

Sapp, J., 'The Struggle for Authority in the Field of Heredity, 1900-1932: New Perspectives on the Rise of Genetics', Journal of the History of Biology, 16 (1983), 311-342 
Schneider, W. H., 'Toward the Improvement of the Human Race: The History of Eugenics in France', Journal of Modern History, 54:2 (1982), 268-291

Schneider, W. H., Quality and Quantity: The Quest for Biological Regeneration in Twentieth-Century France (Cambridge: Cambridge University Press, 1990)

Schwartz Cowan, R., 'Nature and Nurture: The Interplay of Biology and Politics in the Work of Francis Galton', Studies in History of Biology, 1 (1977), 133-208

Scott, J. C., Seeing Like a State: How Certain Schemes to Improve the Human Condition Have Failed (New Haven, CT: Yale University Press, 1988)

Scott, J. W., 'On Language, Gender, and Working-Class History', in Joan Wallach Scott, Gender and the Politics of History (New York: Columbia University Press, 1999), pp. 53-67

Sears, H. D., The Sex Radicals: Free Love in High Victorian America (Lawrence, KS: Regents Press of Kansas, 1977)

Seitler, D., Atavistic Tendencies: The Culture of Science in American Modernity (Minneapolis, MN/London: University of Minnesota Press, 2008)

Simpson, P., 'Bolshevism and "Sexual Revolution": Visualizing New Soviet Woman as the Eugenic Ideal', in F. Brauer and A. Callen (eds), Art, Sex and Eugenics: Corpus Delecti (Aldershot/Burlington, VT: Ashgate, 2008), pp. 209-238

Sinclair, A., Sex and Society in Early Twentieth-Century Spain: Hildegart Rodríguez and the World League for Sexual Reform (Cardiff: University of Wales Press, 2007)

Singer, P., A Darwinian Left: Politics, Evolution and Cooperation (London: Weidenfeld and Nicolson, 1999)

Soloway, R. A., Birth Control and the Population Question in England, 18771930 (Chapel Hill, NC/London: The University of North Carolina Press, 1982)

Soloway, R. A., Demography and Degeneration: Eugenics and the Declining Birthrate in Twentieth-Century Britain (Chapel Hill, NC/London: The University of North Carolina Press, 1995)

Somers, M., 'Narrativity, Narrative Identity, and Social Action', Social Science History, 16 (1992), 591-630

Sonn, R., "“Your Body Is Yours": Anarchism, Birth Control, and Eugenics in Interwar France', Journal of the History of Sexuality, 14:4 (2005), 415-432

Sonn, R., Sex, Violence and the Avant-Garde: Anarchism in Interwar France (University Park, PA: Pennsylvania State University Press, 2010)

Stenstad, G., 'Anarchic Thinking: Breaking the Hold of Monotheistic Ideology on Feminist Philosophy', in Ann Gary and Marilyn Pearsall (eds), Women, Knowledge, and Reality: Explorations in Feminist Philosophy (New York/ London: Routledge, 1992), pp. 331-339

Stepan, N. L., 'The Hour of Eugenics': Race, Gender, and Nation in Latin America (Ithaca, NY/London: Cornell University Press, 1991)

Strawbridge, S., 'Darwin and Victorian social values', in Eric M. Sigsworth (ed.), In Search of Victorian Values: Aspects of Nineteenth-Century Thought and Society (Manchester/New York: Manchester University Press, 1988), pp. 102-115

Suárez Cortina, M., 'Estudio Preliminar', in Manuel Suárez Cortina (ed.) Enrique D. Madrazo: Escritos sobre ciencia y sociedad (Santander: Universidad de Cantabria, 1998), pp. 11-73 
Taguieff, P. A., 'Eugénisme ou décadence? L'exception française', Éthnologie Française, 29 (1994), 81-103

Todes, D. P., 'Darwin's Malthusian Metaphor and Russian Evolutionary Thought', Isis, 78 (1987), 537-551

Todes, D. P., Darwin without Malthus: The Struggle for Existence in Russian Evolutionary Thought (New York/Oxford: Oxford University Press, 1989)

Torre-Mazas, B., Anales del exilio libertario. Tomo I. (Los hombres, las ideas, los hechos) (Toulouse: Ediciones CNT, 1985)

Tort, T., 'The Interminable Decline of Lamarckism in France', trans. Matthew Cobb, in Eve-Marie Engels and Thomas F. Glick (eds), The Reception of Charles Darwin in Europe, vols. I and II (London/New York: Continuum, vol. II, 2008), pp. 329-353

Turcato, D., 'Italian Anarchism as a Transnational Movement, 1885-1915', International Review of Social History, 52:3 (2007), 407-444

Turcato, D., 'The 1896 London Congress: Epilogue or Prologue', in David Berry and Constance Bantman (eds), New Perspectives on Anarchism, Labour and Syndicalism: The Individual, the National and the Transnational (Newcastle: Cambridge Scholars Press, 2010), pp. 110-125

Turda, M., “"To End the Degeneration of a Nation”: Debates on Eugenic Sterilization in Interwar Romania', Medical History, 53 (2009), 77-104

Turda, M., Modernism and Eugenics (Basingstoke: Palgrave Macmillan, 2010)

Turda, M., 'Unity in Diversity: Latin Eugenic Narratives in Europe, c. 1910s-1930s', Contemporanea, 1:20 (2017), 3-30

Turda, M. and Gillette, A., Latin Eugenics in Comparative Perspective (London: Bloomsbury, 2014)

Vallejo, G. and Miranda, M., 'La eugenesia y sus espacios institucionales en Argentina', in Marisa Miranda and Gustavo Vallejo (eds), Darwinismo social y eugenesia en el mundo latino (Buenos Aires: Siglo Veintiuno, 2005), pp. 145-192

Vallejo, G. and Miranda, M., 'Iglesia católica y eugenesia latina: un constructo teórico para el control social (Argentina, 1924-1958)', Asclepio [online], 66:2 (2014)

Vimieiro-Gomes, A. C., Wegner, R. and Souza, V. S. de, 'Guest Editors' Note', História, Ciências, Saúde - Manguinhos, 23:supplement (2016), 10-12

Von Bernhardi, F., Germany and the Next War, trans. Allen H. Powles (London: Edward Arnold, 1914)

Waelti-Walters, J. and Hause, S. C. (eds), Feminisms of the Belle Epoque: A Historical and Literary Anthology (Lincoln, NE/London: University of Nebraska Press, 1994)

Walzer, M., 'The Politics of Michel Foucault', in David Couzens Hoy (ed.), Foucault: A Critical Reader (Oxford: Blackwell, 1986), pp. 51-68

Wanrooij, B. P. F., Storia del pudore. La questione sessuale in Italia 1860-1940 (Venice: Marsilio Editore, 1990)

Weikart, R., From Darwin to Hitler: Evolutionary Ethics, Eugenics, and Racism in Germany (New York: Palgrave Macmillan, 2004)

Weindling, P., Health, Race and German Politics between National Unification and Nazism, 1870-1945 (Cambridge: Cambridge University Press, 1989) 
Weinstein, D., Equal Freedom and Utility: Herbert Spencer's Liberal Utilitarianism (Cambridge: Cambridge University Press, 1998)

Weiss, S. F., The Nazi Symbiosis: Human Genetics and Politics in the Third Reich (Chicago/London: The University of Chicago Press, 2010)

Whelehan, N., 'Political Violence and Morality in Anarchist Theory and Practice: Luigi Galleani and Peter Kropotkin in Comparative Perspective', Anarchist Studies, 13:2 (2005), 147-168

Woodcock, G., Anarchism: A History of Libertarian Ideas and Movements (London: Penguin, 1970)

Yerrill, P. and Rosser, L., Revolutionary Unionism in Latin America: The FORA in Argentina (London/Doncaster: ASP, 1987)

Young, R. M., "Malthus on Man - In Animals no Moral Restraint”', in B. Dolan (ed.), Malthus, Medicine, and Morality: 'Malthusianism' after 1798 (Amsterdam/Atlanta, GA: Rodopi, 2000), pp. 73-91 